\title{
The relationship between lower serum Magnesium levels and heart rate variability indices
}

\author{
Daniela Matei, Cătălina Luca, Doru Andrițoi, Dragoṣ Sărdaru, Călin Corciovă
}

Corresponding author: Catalina Luca, E-mail address: luca.katalina@yahoo.com

\begin{abstract}
Introduction: Magnesium is required in muscular contraction, neuromuscular conduction, heart functions, and vascular tone. Heart rate variability (HRV) is a non-invasive assessment method of the autonomic nervous system activity which regulates heart rate (HR). Time-domain, frequency-domain and non-linear analysis of the HRV can establish the autonomic tone balance.

Objectives: The purpose of this study was to investigate the relationship between lower serum magnesium levels and HRV indices, and to observe if magnesium supplementation can corrected autonomic functions.

Methods: We analyzed HRV parameters in 30 patients with hypomagnesaemia and 20 age-related healthy subjects.

Results: In control group we found lower values for HR, LF nu and LF/HF ratio ( $\mathrm{p}<0.0002)$ and higher values for HF nu, SD1 when compare with patients with magnesium deficiency, resulting that in supine position there is an enhanced heart rate. In magnesium deficiency group we found increase LF nu, LF/HF ratio suggesting that the sympathovagal balance was affected with a sympathetic overactivity. After magnesium supplementation the HR, LF/HF ratio decrease and RMMSD, pNN50\%, HF, SD1 increase in these patients. Conclusions: Findings from the current study suggest that $\mathrm{Mg}$ supplementation may enhance parasympathetic activity and therefore presenting a positive impact on cardiac autonomic function.
\end{abstract}

Key words: magnesium, deficiency, supplementation, heart rate variability, sympathetic nervous system, parasympathetic nervous system,

\section{Introduction}

Magnesium is a cofactor for more than 300 enzymatic reactions and is required in muscular contraction, neuromuscular conduction, heart functions, and vascular tone [1, 2]. Magnesium $\left(\mathrm{Mg}^{2+}\right)$ inhibits calcium induced cell death, can regulates the activity of ion channels, and the synthesis of ATP, RNA, DNA [1, 3].

$\mathrm{Mg}^{2+}$ deficiency promotes oxidative stress and inflammatory response and can contributes to the pathogenesis of several cardiovascular diseases such as atherosclerosis, hypertension, arrhythmia and sudden death [4-6]. It was reported a high incidence of sudden death on rats with Mg-deficient [7]. Mechanisms of sudden death related to $\mathrm{Mg}$ deficiency were arrhythmias, coronary vasospasm and dysfunction of autonomic nervous system [7].

$\mathrm{Mg}$ in serum is about $0.76-1.15 \mathrm{mmol} / \mathrm{L}$ and when serum magnesium concentration is low then 0.75 $\mathrm{mmol} / \mathrm{L}$ is defined hypomagnesaemia [8].

Two types of tetany are known: manifest and latent (spasmophilia). The manifest tetany due to hypocalcemia is rare while latent tetany or spasmophilia (normocalcemic tetany) resulting from cellular magnesium deficiency and hyperventilation, occurs much more frequently [9]. Signs of spasmophilia may include symptoms such as weakness, fatigue, insomnia, depress mood, loss of appetite, nausea, arrhythmias, muscle fasciculation, tremor and generalized seizures. These disorders can be reverse by oral supplementation of magnesium.

Heart rate variability (HRV) is a non-invasive assessment method of the autonomic nervous system activity which regulates heart rate (HR). Timedomain, frequency-domain and non linear analysis of the HRV can establish the autonomic tone balance. Linear parameters are commonly used in clinical trials. Nonlinear parameters such as the Poincaré plot, Detrended fluctuation analysis (DFA), Approximate Entropy (ApEn) and Sample Entropy (SampEn) are rarely analyzed although, there are proves they are more sensitive than linear parameters to smaller heart rate (HR) modulations $[10,11]$.

Increased HRV reflects a healthy organism which is able to respond appropriately the environmental changes, whereas decreased HRV is a sign of autonomic dysfunction [12]. Recent research has shown that a decreased HRV is associated with risk factors for cardiovascular diseases and sudden cardiac death. The effects of magnesium in reduction of the systolic and diastolic arterial blood pressure are known, but the studies that try to correlate serum magnesium concentration with HRV are very scarce [13]. 
In the present study we try to explore the relationship between lower serum magnesium levels and HRV indices, and to observe if magnesium supplementation can corrected autonomic functions.

\section{Patients and Methods}

2.1. Participant recruitment and inclusion criteria

The study involved 30 (12 males and 18 females) patients with hypomagnesaemia and 20 (10 males and 10 females) age-related healthy subjects. The volunteers were recruited mainly from students of the Faculty of Medical Bioengineering, University of Medicine and Pharmacy "Grigore T. Popa" from Iasi. The ages of both groups ranged between 20-35 years. Subjects with medical history of diabetes mellitus, hypertension, heart diseases, arrhythmias, atrioventricular block or bundle branch blocks, seizures in the past 6 months, smoking were excluded from the study. Inclusion criteria for the controls were: the absence of clinical signs of hypomagnesaemia, normal serum $\mathrm{Mg}^{2+}$ and normal electrocardiogram.

Patients were enrolled after being given a detailed explanation of the study and after the informed consent was signed either by the patient or the responsible caregiver. The study was carried out in accordance with the Helsinki Declaration.

2.2. Clinical, psychological and biochemical assessment

Detailed history, clinical evaluation, blood tests were assessed for all patients included in the study. Height, weight and body mass index (BMI, $\mathrm{kg} / \mathrm{m}^{2}$, calculated as weight divided by height squared) were measured in all subjects. Systolic and diastolic blood pressure (SBP and DBP) were measured in a supine and standing position using an Omron MX blood pressure recorder. The mean arterial blood pressure was determined by the formula: diastolic blood pressure $+[$ (systolic blood pressure - diastolic blood pressure)/3].

2.3. Clinical autonomic function tests and measurement of heart rate variability

For this study short term electrocardiogram recording was acquired during supine for $10 \mathrm{~min}$ using the BIOPAC MP 150 data acquisition system. AcqKnowledge Software version 4.1.1. (BIOPAC Inc., Goleta, CA, USA) was used to analyze and remove from the recorded ECG all noise and ectopic beats. Kubios $\mathrm{HRV}^{\circledR}$ Analysis Software 2.0 for Windows (The Biomedical Signal and Medical Imaging Analysis Group, Department of Applied
Physics, University of Kuopio, Finland) was used to generate the HRV parameters. Data acquisition was performed in a quiet room with temperature between 20 and $22^{\circ} \mathrm{C}$. The data were recorded between 9 and $10 \mathrm{am}$, after an adaptation period of 15 minutes. All individuals were asked to avoid caffeine and alcohol 24 hours before the tests.

Time-domain indices, such as mean heart rate, SDNN (reflects the overall cyclic components of HRV during the recording period), RMSSD (square root of the mean squared differences of successive normal to normal intervals) and the proportion derived by dividing NN50 by the total number of NN intervals (pNN50) were calculated [14]. Using Fast Fourier Transform we analyzed frequency domain indices, such as very low frequency (VLF, 0.0033 to $0.04 \mathrm{~Hz}$ - influenced by the thermoregulatory and renin-angiotensin system), low-frequency (LF, 0.04$0.15 \mathrm{~Hz}, \mathrm{~ms}^{2}$ - represent both sympathetic and parasympathetic activities) and high-frequency (HF, $0.15-0.4 \mathrm{~Hz}, \mathrm{~ms}^{2}$ - characteristic to parasympathetic activity) powers, $\mathrm{LF}$ in normalized units (LF nu $=\mathrm{LF} /$ (TP-VLF), HF in normalized units ( $\mathrm{HF} n u=\mathrm{HF} /(\mathrm{TP}-$ VLF) and the ratio between LF/HF (considered an index of cardiac sympathetic/ parasympathetic tone balance) [15].

For non-linear Poincare plot, Approximate Entropy (ApEn), Sample Entropy (SampEn) and the Detrended Fluctuation Analysis (DFA) parameters were reported. Plotting the RR values of $\mathrm{N}$ on the $\mathrm{x}$ axis, and the $R R$ values of $\mathrm{N}+1$ on the $\mathrm{y}$ axis we obtained Poincare plot. Index $\mathrm{SD}_{1}$ obtained from the Poincare plot was used to determine short-term variability of a nonlinear system [16]. SD1 was correlated with RMSSD and high frequency [17].We also used short-term $\alpha 1$ (calculated from 4-16 beats) scaling exponents of DFA to reveal short-term fluctuation. Normal values of $\alpha$ around 1 are found in healthy subjects; lower values indicate a reduced fractal property of heart rate and have been correlated with mortality in elderly subjects [18].

ApEn was used to quantify the overall complexity and predictability of the signal. A large value of ApEn indicated a regular signal and high values indicate a more irregular signal. This parameter was demonstrated to be influenced by record length; therefore Richman and Moorman developed SampEn which is not record length dependent [19].

HRV was done before and after $\mathrm{Mg}$ supplementation with magnesium citrate in 
combination with Vitamin B6 for 30 days. The amount of magnesium administered per day is still in the discussion, although we preferred to administer $\geq$ $300 \mathrm{mg} \mathrm{Mg}^{2+}$ with adjustment dosages for age, sex and nutritional status [20].

\subsection{Statistical analysis}

Statistical analyses were performed using SPSS, version 4.0.1 (SPSS, USA). The results were expressed as mean \pm standard deviation for normally distributed continuous variables. To determine the differences between the groups the following variables were used: the Mann-Whitney U-test for skew-distributed continuous variables, Test $\mathrm{t}$ Student or variance analysis (ANOVA) for normally distributed continuous variables. The Pearson correlation coefficient $r$ was used for determining relationship between parameters. The values $\mathrm{p}<0.05$ were considered statistically significant.

\section{Results}

3.1. Clinical, biochemical features in the groups study

30 students with hypomagnesaemia (Group 1; 18 women, 12 men) with mean age $24.621 \pm 3.396$ years and 20 healthy subjects (Control; 10 women and 10 men) with mean age $25.050 \pm 3.170$ years were investigated in our study. The groups did not differ by age $(p<0.6571)$ Table 1 . The values of the serum magnesium were decrease in Group 1 when compare with Control group $(0.53 \pm 0.13 \mathrm{mmol} / \mathrm{L}$ vs $1.06 \pm$ $0.14 \mathrm{mmol} / \mathrm{L}, \quad \mathrm{p}<0.0001)$. All students with hypomagnesaemia received $\mathrm{Mg}^{2+}$ supplementation with magnesium citrate in combination with vitamin B6 for 30 days (Group 2). After supplementation the values of $\mathrm{Mg}^{2+}$ increase at $0.92 \pm 0.14 \mathrm{mmol} / \mathrm{L}$ (Table $1)$.

Table 1. General parameters in study groups

\begin{tabular}{|c|c|c|c|c|c|c|}
\hline Parameters & $\begin{array}{l}\text { Control } \\
\mathrm{N}=20\end{array}$ & $\begin{array}{l}\text { Group } 1 \\
\text { Hypomagnesaemia } \\
\mathrm{N}=30\end{array}$ & $\begin{array}{l}\text { Group } 2 \\
\text { Mg } \\
\text { supplementation } \\
\mathrm{N}=30\end{array}$ & $\begin{array}{l}\text { Group } \\
1 \\
\text { vs. } \\
\text { Control }\end{array}$ & $\begin{array}{l}\text { Group } \\
1 \\
\text { vs. } \\
\text { Group } \\
2 \\
\end{array}$ & $\begin{array}{l}\text { Group } \\
2 \\
\text { vs. } \\
\text { Control }\end{array}$ \\
\hline & & & & \multicolumn{3}{|l|}{$\mathrm{p}$ value } \\
\hline Age (years) & $25.050 \pm 3.170$ & $24.621 \pm 3.396$ & $24.724 \pm 3.422$ & 0.6571 & 0.9084 & 0.7373 \\
\hline Height $(\mathrm{cm})$ & $169.850 \pm 7.962$ & $168.345 \pm 6.821$ & $168.379 \pm 6.863$ & 0.4818 & 0.9848 & 0.4327 \\
\hline Weight (Kg) & $68.895 \pm 10.964$ & $62.172 \pm 8.665$ & $62.641 \pm 7.802$ & 0.0223 & 0.8293 & 0.0254 \\
\hline BMI $\left(\mathrm{kg} / \mathrm{m}^{2}\right)$ & $23.970 \pm 3.431$ & $21.898 \pm 2.384$ & $22.067 \pm 2.072$ & 0.0172 & 0.7739 & 0.0206 \\
\hline $\mathrm{SBP}(\mathrm{mmHg})$ & $118.300 \pm 15.048$ & $126.700 \pm 16.957$ & $\begin{array}{l}117.567 \\
15.624 \\
\end{array}$ & 0.0793 & 0.0341 & 0.8697 \\
\hline $\begin{array}{l}\text { DBP } \\
(\mathrm{mmHg})\end{array}$ & $72.550 \pm 10.107$ & $79.367 \pm 15.305$ & $74.900 \pm 12.078$ & 0.0864 & 0.2146 & 0.4763 \\
\hline $\mathrm{HR}(\mathrm{b} / \mathrm{min})$ & $78.900 \pm 12.887$ & $89.033 \pm 15.103$ & $81.933 \pm 9.826$ & 0.0296 & 0.0351 & 0.5102 \\
\hline $\begin{array}{l}\text { Magnesaemia } \\
(\mathrm{mmol} / \mathrm{L})\end{array}$ & $1.06 \pm 0.14$ & $0.53 \pm 0.13$ & $0.92 \pm 0.14$ & $\begin{array}{l}< \\
0.0001\end{array}$ & $\begin{array}{l}< \\
0.0001\end{array}$ & 0.2691 \\
\hline
\end{tabular}

The body mass indices was decrease in Group 1 $\left(21.898 \pm 2.384 \mathrm{Kg} / \mathrm{m}^{2}\right)$ when compare with Control $\left(23.970 \pm 3.431 \mathrm{Kg} / \mathrm{m}^{2}\right)$ with statistical signification $(\mathrm{p}<0.0172)$. After magnesium supplementation the body mass indices increase in Group 2 (22.067 \pm $2.072 \mathrm{Kg} / \mathrm{m}^{2}$ ) but the difference remains when comparing with Control group with $\mathrm{p}<0.0206$.
The values for systolic and diastolic blood pressures did not differ between Group 1 and Control, but after magnesium supplementation we observed a reduction of the systolic blood pressure $(126.700 \pm$ $16.957 \mathrm{mmHg}$ vs $117.567 \pm 15.624 \mathrm{mmHg}$ ) with $\mathrm{p}<0.0341$. It is also noted that increased heart rate in the hypomagnesaemia group is reduced after supplementation of this ion $(\mathrm{p}<0.0351)$. 
3.2. Clinical autonomic function tests and measurement of heart rate variability

Mean RR was $789.746 \pm 67.622 \mathrm{~ms}$ in the control group and $719.151 \pm 85.777 \mathrm{~ms}$ in the Group 1 with $\mathrm{p}<0.0033$. After the magnesium supplementation the $\mathrm{RR}$ mean increase at $793.950 \pm 92.339 \mathrm{~ms}$ with $\mathrm{p}<0.0019$.

SDNN, RMSSD, pNN50\%, parameters which correlate with the parasympathetic activity, were decrease in hypomagnesaemia group and after magnesium administration these parameters increase reaching values similar to those in the control group

Table 2.

Table 2. Heart rate variability parameters in resting state in groups study

\begin{tabular}{|c|c|c|c|c|c|c|}
\hline $\begin{array}{l}\text { HRV } \\
\text { parameters } \\
\text { in } \\
\text { resting } \\
\text { state } \\
\end{array}$ & $\begin{array}{l}\text { Control } \\
\mathrm{N}=20\end{array}$ & $\begin{array}{l}\text { Group } \\
\text { Hypomagnesaemia } \\
\mathrm{N}=30\end{array}$ & $\begin{array}{l}\text { Group } 2 \\
\mathrm{Mg} \\
\text { supplementation } \\
\mathrm{N}=30\end{array}$ & $\begin{array}{l}\text { Group } \\
1 \\
\text { vs. } \\
\text { Control }\end{array}$ & $\begin{array}{l}\text { Group } \\
1 \\
\text { vs. } \\
\text { Group } \\
2 \\
\end{array}$ & $\begin{array}{l}\text { Group } \\
2 \\
\text { vs. } \\
\text { Control }\end{array}$ \\
\hline & & & & \multicolumn{3}{|l|}{$\mathrm{p}$ value } \\
\hline RR & $789.746 \pm 67.622$ & $719.151 \pm 85.777$ & $\begin{array}{ll}793.950 & \pm \\
92.339 & \\
\end{array}$ & 0.0033 & 0.0019 & 0.8622 \\
\hline SDNN & $72.200 \pm 23.647$ & $56.103 \pm 20.383$ & $68.513 \pm 22.143$ & 0.0143 & 0.0362 & 0.5772 \\
\hline HR & $73.550 \pm 7.207$ & $81.517 \pm 13.276$ & $75.833 \pm 7.670$ & 0.0184 & 0.0479 & 0.1602 \\
\hline RMSSD & $77.214 \pm 33.541$ & $54.580 \pm 32.675$ & $72.840 \pm 35.940$ & 0.0216 & 0.0440 & 0.6671 \\
\hline pNN50\% & $15.300 \pm 11.449$ & $9.040 \pm 7.084$ & $12.409 \pm 7.336$ & $\mathbf{0 . 0 2 0 7}$ & 0.0755 & 0.2813 \\
\hline VLF & $536.333 \pm 474.814$ & $275.450 \pm 220.629$ & $\begin{array}{l}462.667 \\
377.294\end{array}$ & 0.0263 & 0.0513 & 0.5085 \\
\hline LF & $1813.55 \pm 880.67$ & $\begin{array}{l}1348.700 \\
822.231\end{array}$ & $\begin{array}{l}2243.033 \\
1775.669\end{array}$ & 0.0629 & 0.0151 & 0.3222 \\
\hline $\mathrm{HF}$ & $1595.100 \pm 814.888$ & $736.667 \pm 682.566$ & $\begin{array}{l}1757.133 \\
1525.387\end{array}$ & 0.0002 & 0.0014 & 0.6659 \\
\hline LF nu & $53.035 \pm 8.858$ & $66.317 \pm 11.359$ & $55.383 \pm 6.464$ & $\begin{array}{l}< \\
0.0001\end{array}$ & $\begin{array}{l}< \\
0.0001\end{array}$ & 0.2837 \\
\hline HFnu & $46.474 \pm 9.202$ & $33.467 \pm 11.414$ & $44.430 \pm 6.828$ & $\begin{array}{l}< \\
0.0001\end{array}$ & $\begin{array}{l}< \\
0.0001\end{array}$ & 0.3717 \\
\hline $\mathrm{LF} / \mathrm{HF}$ & $1.113 \pm 0.387$ & $2.403 \pm 1.087$ & $1.345 \pm 0.278$ & $\begin{array}{l}< \\
0.0001\end{array}$ & $\begin{array}{l}< \\
0.0001\end{array}$ & 0.0173 \\
\hline SD1 & $54.605 \pm 23.792$ & $38.607 \pm 23.196$ & $45.457 \pm 20.477$ & 0.0221 & 0.2302 & 0.1534 \\
\hline Alfa1 & $1.111 \pm 0.270$ & $0.882 \pm 0.168$ & $0.977 \pm 0.213$ & 0.0014 & $\mathbf{0 . 0 5 2 7}$ & 0.0696 \\
\hline SampEn & $0.858 \pm 0.208$ & $0.812 \pm 0.251$ & $1.007 \pm 0.392$ & 0.4760 & 0.0541 & 0.0714 \\
\hline ApEn & $0.802 \pm 0.195$ & $0.879 \pm 0.215$ & $0.875 \pm 0.292$ & 0.2073 & 0.9505 & 0.3361 \\
\hline
\end{tabular}

The value of HF and HF nu were decrease in Group $1\left(736.667 \pm 682.566 \mathrm{~ms}^{2} ; 33.467 \pm 11.414\right)$ in comparison to Control group (1595.100 \pm $\left.814.888 \mathrm{~ms}^{2} ; 46.474 \pm 9.202\right)$ with $\mathrm{p}<0.0002$ and
Analysis of frequency domain indices revealed that before magnesium supplementation LF indices did not differ between the groups (Group 1: 1348.700 $\pm 822.231 \mathrm{~ms}^{2}$ vs $1813.55 \pm 880.67 \mathrm{~ms}^{2}$ control group, $\mathrm{p}<0.0629$ ), but LF nu were increase in Group $1(66.317 \pm 11.359)$ vs control $(53.035 \pm 8.858)$ with $\mathrm{p}<0.0001$. After $\mathrm{Mg}^{2+}$ administration the value of $\mathrm{LF}$ increase $2243.033 \pm 1775.669 \mathrm{~ms}^{2}$ with $\mathrm{p}<0.0151$ and LF nu decrease $(55.383 \pm 6.464, \mathrm{p}<0.0001)$ when compare with the value before $\mathrm{Mg}^{2+}$ intake. 
$(p<0.0014, p<0.0001)$ reaching values similar to those in the control group Table 2.

LF/HF ratio was significantly increased in Group $1(2.403 \pm 1.087)$ compared with control group $(1.113 \pm 0.387)$ with $p<0.0001$, indicating enhanced sympathetic activity and reduced vagal activity in magnesium deficiency group in resting state. After $\mathrm{Mg}^{2+}$ intake the LF/HF ratio decrease at $1.345 \pm$ 0.278 , with $\mathrm{p}<0.0173$ when compare with Control group (Table 2).

Poincare plot index SD1 was greater in healthy controls vs Group $1(p<0.0221)$, confirming the enhancement of vagal modulation in supine rest. After the $\mathrm{Mg}^{2+}$ supplementation the SD1 mean in group 1 normalized. The increase in alfa 1 of DFA was found in healthy subjects $(p<0.0014)$ when compare with hypomagnesaemia subjects. SampEn, ApEn weren't significantly modified in healthy subjects and Group 1. After $\mathrm{Mg}^{2+}$ intake the alfa 1 and SampEn increased with $p<0.05$.

In Pearson correlation $\mathrm{Mg}^{2+}$ correlated positively with RMSSD $(\mathrm{r}=0.48, \mathrm{p}<0.0032)$, HF $(\mathrm{r}=0.45$, $\mathrm{p}<0.001)$, HF nu $(r=0.45, p<0.0008)$, SD1 $(r=0.47$, $\mathrm{p}<0.0033)$ and negatively with heart rate $(\mathrm{r}=-0.48$, $\mathrm{p}<0.003)$, LF nu $(\mathrm{r}=-0.46, \mathrm{p}<0.0007), \mathrm{LF} / \mathrm{HF}$ ratio $(\mathrm{r}=-0.57, \mathrm{p}<0.0001)$, systolic blood pressure $(\mathrm{r}=$ $0.26, p<0.0173$ ). Frequency domain measures of heart rate variability analysis revealed that LF nu and $\mathrm{HF}$ nu were correlated with $\mathrm{LF} / \mathrm{HF}(\mathrm{r}=0.86$, $\mathrm{p}<0.0001)$ and $(\mathrm{r}=-0.85, \mathrm{p}<0.0001)$ respectively.

\section{Discussions}

Lower magnesium concentration was associated with increased risk of cardiovascular mortality [21, 22], while magnesium supplementation was found to reduce the risk of cardiovascular events [23, 24]. Magnesium concentration is correlated directly with parasympathetic indices of HRV and may enhance the parasympathetic activity [21-23].

$\mathrm{Mg}$ deficiency produces accumulation of intracellular $\mathrm{Ca}^{2+}$ and may lead to enhanced automaticity, which can increase arrhythmogenic activity and can contribute to cardiac cell hypertrophy, necrosis, or apoptosis [25].

Low $\mathrm{Mg}^{2+}$ levels have been shown to adjust the expression of interleukin-6, TNF-a, and C-reactive protein (CRP), thereby producing inflammation and endothelial dysfunction [26, 27].

Normally, the sympathetic and parasympathetic nervous system activities are in dynamic balance thus indicating a healthy physiological system. The autonomic imbalance described by increased sympathetic activity and suppressed parasympathetic activity is associated with an increased risk of diseases such as cardiovascular, neuroendocrine, digestive and psychiatric disorders.

Spectral analysis of HRV provides a sensitive non-invasive measure of cardiac autonomic regulation. High frequency (HF) power reflects vagal activity and low frequency (LF) power is thought to measure a combination of vagal and sympathetic nervous system activity. As such, the LF component is less easily interpretable, although the $\mathrm{LF} / \mathrm{HF}$ ratio is accepted as an indicator of sympathovagal balance [15].

In the present study, the HRV analysis revealed that control group had significantly lower values for HR $(p<0.0184)$, LF nu $(p<0.0253)$ and LF/HF ratio $(\mathrm{p}<0.0002)$ when compare with patiens with $\mathrm{Mg}^{2+}$ deficiency. Also in the same patients we found higher values of $\mathrm{HF} \mathrm{nu}(\mathrm{p}<0.0273)$ and SD1 $(p<0.0471)$ resulting that in supine position there is an enhanced heart rate vagal modulation in control group. A significant increase in LF nu, LF/HF ratio and significant decrease in HF nu and SD1 were found in $\mathrm{Mg}$ deficiency suggesting that the sympathovagal balance were affected with a sympathetic overactivity in these patients. Increase in non-linear indexes was associated with vagal modulation and its decrease is usually interpreted by the result of an increased sympathetic drive and vagal withdrawal [28].

After Mg supplementation the HR $(p<0.0479)$, $\mathrm{LF} / \mathrm{HF}$ ratio $(\mathrm{p}<0.0014)$ decrease and SDNN $(\mathrm{p}<0.0453), \quad$ RMMSD $\quad(p<0.0447), \quad$ pNN50\% $(p<0.0005)$, HF $(p<0.0065)$, SD1 $(p<0.0401)$ were found increase in these patients. Findings from the current study suggest that Mg supplementation may enhance parasympathetic activity and therefore presenting a positive impact on cardiac autonomic function. In Pearson correlation we found a negative correlation between serum $\mathrm{Mg}^{2+}$ levels and LF/HF.

Our study is in agreement with other studies demonstrating that $\mathrm{Mg}$ administration improves cardiac function [28, 29]. More over it has been proved that magnesium supplementation was inversely associated with mortality from ischemic strokes, coronary heart disease, and heart failure in women [30].

The main limitation of our study was the relatively small sample size, which makes it difficult 
to draw more specific conclusions. Also the very short time of treatment ( 1 month) is another factor which contributes to the analysis of recorded data. Therefore, further studies are needed to track the influence of $\mathrm{Mg}$ supplementation on HRV parameters over a longer period of time and to established the role of magnesium in the prevention and treatment of cardiovascular diseases.

\section{Conclusions}

In conclusion, both linear and non-linear parameters of HRV measured in our study demonstrated an increased vagal influence on heart rate and an attenuated sympathetic tone in patients with normal values of serum $\mathrm{Mg}$. The $\mathrm{Mg}$ deficiency group was characterized by a high sympathetic tone, expressed by high heart rate, $\mathrm{LF} / \mathrm{HF}$ ratio and altered nonlinear dynamic parameters. After one month of $\mathrm{Mg}$ supplementation the autonomic balance has been restored. $\mathrm{Mg}^{2+}$ by stimulating parasympathetic activity with effect over cardiac function has important role in cardiac protection.

\section{Acknowledgements}

The support of the staff at the Biomedical Sciences Department, Faculty of Medical Bioengineering, as well as the enduring cooperation of the participants in this study is gratefully acknowledged.

\section{Conflict of Interest Statement:}

The authors declare that have no conflict of interests.

\section{References}

1. Rude, R.K. Magnesium. In Modern Nutrition in Health and Disease, 11th ed.; Ross, A.C., Caballero, B., Cousins, R.J., Tucker, K.L., Ziegler, T.R., Eds.; Lippincott Williams \& Wilkins: Baltimore, MA, USA, 2012; pp. 159-175.

2. Maier JA. Endothelial cells and magnesium: implications in atherosclerosis. Clin Sci (Lond) 2012;122:397-407

3. Kawano S. Dual mechanisms of $\mathrm{Mg} 2+$ block of ryanodine receptor $\mathrm{Ca} 2+$ release channel from cardiac sarcoplasmic reticulum.Receptors Channels. 1998;5(6):405-16.
4. Salvemini D, Doyle TM, Cuzzocrea S. Superoxide, peroxynitrite and oxidative/nitrative stress in inflammation. BiochemSoc Trans. 2006; 34: 965-70.

5. A. Mazur, J. A. M. Maier, E. Rock, E. Gueux,W. Nowacki,Y. Rayssiguier, "Magnesium and the inflammatory response: potential physiopathological implications," Archives of Biochemistry and Biophysics 2007; 458(1): 48-56.

6. Ferre S, Baldoli E, Leidi M, Maier JA. Magnesium deficiency promotes a proatherogenic phenotype in cultured human endothelial cells via activation of NFkB. Biochim Biophys Acta 2010;1802: 952-958.

7. Fiset C, Kargacin ME, Kondo CS, Lester WM, Duff HJ. Hypomagnesemia: characterization of a model of sudden cardiac death. J Am CollCardiol. 1996; 27:17711776.

8. Witkowski M, Hubert J, Mazur A. Methods of assessment of magnesium status in humans: a systematic review. Magnesium Res 2011; 24: $163-80$.

9. Toruńska K. Tetany as a difficult diagnostic problem in the neurological outpatient department. NeurolNeurochir Pol. 2003; 37(3):653-64.

10. Makikallio TH, Tapanainen JM, Tulppo MP, Huikuri HV. Clinical applicability of heart rate variability analysis by methods based on nonlinear dynamics. Card Electro physiol Rev 2002; 6: 250-5.

11. Constantinescu V, Matei D, Costache V, Cuciureanu D, Arsenescu-Georgescu C. Linear and nonlinear parameters of heart rate variability in ischemic stroke patients. Neurol Neurochir Pol. 2017 Oct 11. pii: S00283843(17)30196-2.

doi: 10.1016/j.pjnns.2017.10.002.

12. Thayer JF, Hansen AL, Saus-Rose E, Johnsen $\mathrm{BH}$. Heart rate variability, prefrontal neural function, and cognitive performance: the neurovisceral integration perspective on selfregulation, adaptation, and health. Ann Behav Med. 2009; 37(2):141-53.

13. Martynov AI, Akatova EV. Fifteen years experience of the use of magnesium preparations in patients with mitral valve prolapse. Kardiologia. 2011;51(6):60-5. 
14. Constantinescu V, Matei D, Cuciureanu D, Corciova C, Ignat B, Popescu CD. Cortical modulation of cardiac autonomic activity in ischemic stroke patients. Acta Neurol Belg. 2016;116(4):473-480.

15. Task Force of the European Society of Cardiology the North American Society of Pacing Electrophysiology. Heart rate variability: standards of measurement, physiological interpretation, and clinical use. Circulation. 1996; 93(5):1043-65.

16. Brennan M, Palaniswami M, Kamen P. Do existing measures of Poincare plot geometry reflect nonlinear features of heart rate variability? IEEE Trans Biomed Eng. 2001; 48: $1342-1347$.

17. Kiviniemi Antti. Measurement of cardiac vagal outflow by beat-to-beat R-R interval Dynamics. Acta Univ. Oul. 2006; D 887. Oulu, Finland.

18. Makikallio TH, Huikuri HV, Makikallio A, Sourander LB, Mitrani RD, Castellanos A, Myerburg RJ. Prediction of sudden cardiac death by fractal analysis of heart rate variability in elderly subjects. J Am CollCardiol. 2001;37(5):1395-402.

19. Richman JS, Moorman JR. Physiological time-series analysis using approximate entropy and sample entropy. Am J Physiol Heart Circ Physiol.2000; 278(6):H2039-49.

20. Jahnen-Dechent, J.; Ketteler, M. Magnesium basics. Clin.Kidney J. 2012, 5, i3-i14.

21. Reffelmann T, Ittermann T, Dörr M, Völzke H, Reinthaler M, Petersmann A, Felix SB. Low serum magnesium concentrations predict cardiovascular and all-cause mortality. Atherosclerosis. 2011; 219(1):280-4.

22. Sakaguchi Y, Fujii N, Shoji T, Hayashi T, Rakugi H, Isaka Y. Hypomagnesemia is a significant predictor of cardiovascular and non-cardiovascular mortality in patients undergoing hemodialysis. Kidney Int 2014 Jan;85(1):174-181.

23. Guasch-Ferre M, Bullo M, Estruch R, Corella D, Martinez-Gonzalez MA, Ros E, et al. Dietary magnesium intake is inversely associated with mortality in adults at high cardiovascular disease risk. J Nutr 2014;144(1):55-60.
24. Hruby A, O'Donnell CJ, Jacques PF, Meigs JB, Hoffmann U, McKeown NM. Magnesium intake is inversely associated with coronary artery calcification: the Framingham Heart Study. JACC Cardiovasc Imaging 2014;7(1):59-69.

25. Günther T. Concentration, compartimentation and metabolic function of intracellular free MG2+ .Magnes Res. 2006; 19: 225-236.

26. Chacko SA, Song Y, Nathan L, Tinker L, de Boer IH, Tylavsky F, Wallace R, Liu S. Relations of dietary magnesium intake to biomarkers of inflammation and endothelial dysfunction in an ethnically diverse cohort of postmenopausal women. Diabetes Care 2010;33:304-10.

27. Maier JA, Malpuech-Brugère $\mathrm{C}$, Zimowska $\mathrm{W}$, et al. Low magnesium promotes endothelial cell dysfunction: implications for atherosclerosis, inflammation and thrombosis. BiochimBiophysActa. 2004;1689:13-21.

28. Almoznino-Sarafian D, Sarafian G, Berman S, Shteinshnaider M, Tzur I, Cohen N, Gorelik O. Magnesium administration may improve heart rate variability in patients with heart failure. NutrMetabCardiovasc Dis. 2009;19(9):641-5

29. Yokoyama A, Kikuchi K, Kawamura Y. Heart rate variability, arrhythmia and magnesium in hemodialysis patients. Clin Calcium. 2005;15(2):226-32.

30. Zhang $\mathrm{W}$, Iso $\mathrm{H}$, Ohira $\mathrm{T}$, Date $\mathrm{C}$, Tamakoshi A, et al. JACC Study Group. Associations of dietary magnesium intake with mortality from cardiovascular disease: the JACC study. Atherosclerosis 2012; 221: 587-595. 